\title{
Padronização do teste de tetrazólio em sementes de Parkia velutina Benoist (Leguminosae - Mimosoideae)
}

\begin{abstract}
Angela Maria da Silva MENDES ${ }^{1}$, Adriana de Araújo BASTOS², Maria da Glória Gonçalves de MELO³
RESUMO

O trabalho teve por objetivo determinar métodos de pré-condicionamento e concentraçôes da solução de tetrazólio na avaliação da qualidade de sementes de Parkia velutina Benoist. Os tratamentos pré-condicionantes das sementes foram avaliados com três métodos de escarificação: desponte na região oposta ao hilo, punção na região mediana e lixa nos dois lados da semente com posterior embebição em $200 \mathrm{ml}$ de água para cada 25 sementes e permanência em câmara a $30{ }^{\circ} \mathrm{C}$ por 16 horas. As concentraçôes da solução de tetrazólio testadas foram: $1,0 \%, 0,5 \%$ e $0,1 \%$ por duas horas na temperatura de $40{ }^{\circ} \mathrm{C}$. $\mathrm{O}$ tratamento de pré-condicionamento mais eficiente foi a combinação do desponte e lixamento nos dois lados da semente. A concentraçáo de tetrazólio a $0,5 \%$ pode ser utilizada para avaliar a viabilidade das sementes de P. velutina como complemento ao teste de germinaçáo. $\mathrm{O}$ teste de tetrazólio se mostrou eficiente na caracterização de lesóes ocasionadas por insetos e danos mecânicos em sementes de P. velutina.
\end{abstract}

PALAVRAS-CHAVE: Qualidade de sementes, análise de sementes, espécie florestal tropical, teste de germinaçáo.

\section{Tetrazolium test in Parkia velutina Benoist seeds (Leguminosae - Mimosoideae)}

\begin{abstract}
This manuscript aimed to determine methods of daily pre-conditioning and concentrations of the tetrazolium solution for evaluating the quality of Parkia velutina Benoist seeds. The daily pre-condicionanting seed treatments were evaluated using three scarification methods: coating cutting on the opposite side of the hilum region, puncture in the medium region and scarification with sandpaper on both sides of the seed, followed by soaking each of the 25 seeds in $200 \mathrm{ml}$ of wate and permanence in chamber $30{ }^{\circ} \mathrm{C}$ for 16 hours. The concentrations of the tetrazolium solution tested were $1.0 \%, 0.5 \%$ and $0.1 \%$ for two hours at $40{ }^{\circ} \mathrm{C}$. The more efficient daily pre-conditioning treatlment was a combination of the coating cutting and the scarification $\mathrm{n}$ both sides of the seed. The $0.5 \%$ tetrazolium concentration can be used to evaluate the viability of P. velutina seeds as complement to the germination test. The tetrazolium test showed its efficiency in the characterization of injuries caused by insects and mechanical damages in $P$. velutina seeds.
\end{abstract}

KEYWORDS: Seed quality, seeds analysis, tropical forest species, germination test.

\footnotetext{
1 Universidade do Estado do Amazonas. E-mail: amendes@uea.edu.br

2 Universidade do Estado do Amazonas. E-mail: adaba@uea.edu.br

3 Universidade do Estado do Amazonas. E-mail: mgmelo@uea.edu.br
} 


\section{INTRODUÇÃO}

A produção de sementes de espécies florestais ganhou grande importância para a formação de mudas a serem utilizadas em programas de reposição florestal, recuperação de áreas degradadas, arborização urbana e a preservação das espécies florestais nativas em extinção, entre outras atividades, que necessitam deste insumo (Vieira et al., 2001). Segundo Rosinha (1981) um dos componentes, senão o mais importante, de um programa de produção de semente é a pesquisa, a qual fornece a base e sobre a qual se apóiam os demais elementos do sistema.

Um dos fatores básicos para o êxito em atividades como recuperação de áreas degradadas e/ou reflorestamento é utilizar espécies adequadas ao habitat das diferentes regiôes, bem como, usar sementes de boa qualidade fisiológica. Desta forma torna-se necessário um bom conhecimento da espécie que se vai trabalhar, evitando-se assim, situações que podem inviabilizar o sucesso destas atividades (Araújo-Neto et al., 2002).

Parkia velutina Benoist pertence à família Leguminosae, sub-família Mimosoideae. A espécie é conhecida popularmente no Brasil como corezeiro e visgueiro (Hopkins, 1986; Silva et al., 2004). Em Coari, município do Amazonas, onde a espécie ocorre em abundância recebe o nome de angicoda-folha-pequena. O gênero Parkia apresenta uma grande diversidade na Amazônia, com árvores de grande porte que ocorrem na floresta de terra-firme, várzea sazonal, floresta secundária, e no norte da América do Sul, onde existem 17 espécies (Hopkins, 1986).

Oliveira et al. (1989) comentam que para o manejo sustentável de qualquer espécie florestal, é necessário um amplo conhecimento de suas características. A pesquisa em tecnologia de sementes tem buscado incessantemente modos de desenvolver ou aprimorar testes que possibilitem a avaliação da qualidade das sementes. Informaçôes sobre sementes florestais, especialmente no que diz respeito à padronizaçáo e ao aperfeiçoamento de métodos de análise, têm sido motivos de estudo por parte de pesquisadores e analistas de sementes, em função da não-existência de prescrições para a condução de teste de germinação para espécies florestais nativas.

A avaliação da qualidade fisiológica é um parâmetro importante a ser considerado em um programa de produção de sementes, e, atualmente, testes que fornecem resultados em período de tempo relativamente curto são os mais demandados para agilizar as tomadas de decisão nas diferentes etapas do processo produtivo, especialmente na fase de pós-colheita (Bhering et al., 2005). A maneira confiável para conhecer a qualidade das sementes é efetuar a análise e a interpretação correta dos resultados. Dessa maneira, pode-se fornecer uma garantia para comerciantes e produtores, diminuindo o risco de aquisiçấo de sementes com qualidade desconhecida e cotação de preço do produto náo compatível com o valor real (Macedo, 2006).

$\mathrm{O}$ método rotineiro para determinar a qualidade das sementes é o teste de germinação, que, embora muito útil, requer um período relativamente longo para se obter resultados, principalmente quando se considera o interesse comercial dos produtores de sementes. Neste contexto, segundo Bhering et al. (2005), o teste de tetrazólio tem se mostrado uma alternativa promissora pela qualidade e rapidez na determinação da viabilidade e do vigor da semente.

$\mathrm{Na}$ realizaçấo do teste de tetrazólio são indicados procedimentos, chamados de pré-condicionamento, que visam a penetraçáo da soluçáo nos tecidos de interesse a serem avaliados. Em sementes de espécies florestais, diversos tratamentos de pré-condicionamento vêm sendo utilizados, como corte, escarificação e embebição em água. Além do pré-condicionamento, a utilização de concentração da solução de tetrazólio, tempo e temperatura de condicionamento e avaliação adequada da coloração das sementes, săo fundamentais para que se obtenham resultados confiáveis sobre a qualidade (Oliveira et al., 2005).

Este estudo teve por objetivo padronizar a eficiência de métodos de pré-condicionamento e concentraçóes da solução de tetrazólio na avaliação da qualidade de sementes de Parkia velutina Benoist.

\section{MATERIAL E MÉTODOS}

As sementes foram coletadas de matrizes identificadas e selecionadas, em área de floresta natural, na Base de Operaçóes Geólogo Pedro de Moura, Coari, AM. A pesquisa foi desenvolvida no Laboratório de Sementes da Escola Superior de Tecnologia (EST), da Universidade do Estado do Amazonas (UEA).

Foi considerado lote de sementes o número da coleta nas árvores matrizes, ou seja, coleta 1 de julho de 2004. Após beneficiamento e secagem, as sementes foram submetidas a tratamento de choque térmico (congelamento), na temperatura de $-18^{\circ} \mathrm{C}$ por 24 horas com o objetivo de eliminar de insetos predadores. Em seguida, após voltar a temperatura ambiente, as sementes foram acondicionadas em recipientes de vidro fechados e estes, armazenados em geladeira à temperatura média de $7{ }^{\circ} \mathrm{C}$, durante 30 meses.

As sementes utilizadas em todos os experimentos estavam armazenadas por 30 meses. Antes de montar os experimentos, o teor de água das sementes foi determinado novamente, utilizando duas repetiçóes de cinco sementes cortadas, em estufa à temperatura de $105^{\circ} \mathrm{C} \pm 2^{\circ} \mathrm{C}$, por 24 horas (Mendes et al., 2006). 


\section{TESTE DE GERMINAÇÃO}

As sementes foram submetidas ao tratamento prégerminativo para a superação da dormência tegumentar, utilizado a escarificação química com ácido sulfúrico concentrado $\left(\mathrm{H}_{2} \mathrm{SO}_{4}\right)$ por 15 minutos, em seguida foram lavadas com água corrente até a completa eliminação dos resíduos.

O teste de germinação foi feito para comparar a viabilidade das sementes com o teste de tetrazólio. O experimento foi conduzido com quatro repetiçóes de 25 sementes, em câmara de germinação a $30^{\circ} \mathrm{C}$ e fotoperíodo de 12 horas. Foi utilizado como substrato, vermiculita de textura média, autoclavada e umedecida com água destilada em 2,5 seu peso. Os critérios adotados para avaliar a germinação foram a emissão da raiz primária $(5 \mathrm{~mm})$ e a formaçáo de plântula normal (raiz primária bem desenvolvida, hipocótilo reto e liberaçáo total do primeiro par de eofilo) e, a viabilidade foi expressa em porcentagem. A germinação foi acompanhada diariamente até a germinação de todas as sementes.

\section{PRÉ-CONDICIONAMENTO}

As sementes foram submetidas a três métodos de précondicionamento para facilitar a retirada do tegumento: escarificação mecânica por desponte na região oposta ao hilo, punçấo na regiâo mediana em um dos cotilédones e lixamento nas laterais da semente.

Após os tratamentos, as sementes foram imersas em 200 $\mathrm{ml}$ de água destilada para cada 25 sementes, em caixa plástica (gerbox) por 16 horas, e colocadas em câmara regulada na temperatura de $30^{\circ} \mathrm{C}$. Decorrido este período, os tegumentos das sementes foram cuidadosamente retirados e os embrióes colocados em copos plásticos descartáveis, sendo totalmente submersos nas diferentes concentraçóes de tetrazólio. $\mathrm{O}$ experimento foi organizado em quatro repetiçóes de 25 sementes.

\section{EXPOSIÇÃO DAS SEMENTES À SOLUÇÃO DE TETRAZÓLIO}

Foram testadas as concentraçôes de $1,0 \%, 0,5 \%$ e $0,1 \%$, utilizando 100 sementes divididas em quatro repetiçóes de 25 . Os embrióes foram imersos em $40 \mathrm{ml}$ de soluçâo para cada repetição, e mantidos em câmara à temperatura de $40^{\circ} \mathrm{C}$, no escuro por duas horas, para finalizar o processo de coloração de acordo com metodologia de França Neto et al. (1998).

Após a finalização da coloraçáo, os embriōes foram lavados em água corrente e mantidos submersos até o momento da análise. Os embriôes foram seccionados longitudinalmente entre os cotilédones (com o cuidado para que o eixo embrionário fosse dividido ao meio nessa secção).

Para a interpretação dos resultados, cada embrião, separadamente, foi analisado e classificado em classe de viabilidade de $\mathrm{C} 1$ a $\mathrm{C} 8$. A somatória do percentual das classes
1 a 3 indica o índice de vigor e a somatória dos percentuais das classes de 1 a 5 a viabilidade do lote (França Neto et al., 1998). Para caracterizar os níveis de viabilidade, dentro de cada classe foi realizada observando-se a presença e a localização do dano nas estruturas embrionárias. A diferenciação de cores dos tecidos foi feita de acordo com França Neto (1999): vermelho brilhante ou rosa (tecido vivo e vigoroso), vermelho carmim forte (tecido em deterioração) e branco leitoso (tecido morto). A viabilidade foi expressa em porcentagem de sementes presentes viáveis nas diferentes categorias.

O experimento foi organizado em delineamento inteiramente ao acaso, com quatro repetiçóes de 25 sementes para cada tratamento. Foi aplicada a Análise de Variância (ANOVA) para testar o grau de significância entre as concentraçôes de tetrazólio e o teste de germinação. Para as médias significativas foi aplicado o Teste de Tukey a 5\% de probabilidade.

\section{RESULTADOS E DISCUSSÃO}

\section{TESTE DE GERMINAÇÃO}

O lote de sementes de $P$. velutina utilizado apresentou $11,3 \%$ de teor de água, no momento da instalação do experimento. Houve uma pequena perda de $0,3 \%$ do teor de água durante o armazenamento (30 meses), o teor de água inicial (antes do armazenamento) foi de 11,6\%. O teste de germinação revelou $96 \%$ de emissão de raiz primária e $94 \%$ de formação de plântulas normais.

\section{PRÉ-CONDICIONAMENTO}

O principal objetivo do pré-condicionamento em sementes é facilitar a penetração da solução de tetrazólio através dos tegumentos, utilizando cortes ou punçôes. Sendo que para algumas espécies, apenas esses procedimentos não são suficientes para essa penetração, como é o caso de $P$. velutina, que necessitou da retirada completa do tegumento. O précondicionamento em P. velutina teve por objetivo facilitar a retirada completa do tegumento, sem injúrias mecânicas, expondo o embriấo e assim facilitar a penetração da solução de tetrazólio para uma coloraçáo mais uniforme.

O primeiro teste foi realizado com três tratamentos précondicionantes: desponte, punçáo e lixa, colocados para embeber por 16 horas a $25^{\circ} \mathrm{C}$, conforme França Neto et al. (1998) para as sementes de leguminosas que não apresentam permeabilidade do tegumento. Porém, os resultados não foram satisfatórios, pois as sementes submetidas à punção embeberam somente uma fração mínima do tegumento próximo ao local perfurado como pode ser observado na figura 1. Enquanto que as sementes submetidas ao desponte não hidrataram suficientemente para facilitar a retirada do tegumento; as mesmas embeberam até a metade do seu 
comprimento, próximo ao local onde foi feito o desponte (Figura 1B). Para as sementes submetidas ao lixamento nas laterais, aproximadamente $50 \%$ destas hidrataram totalmente, amolecendo o tegumento suficientemente para sua retirada com facilidade; em torno de $35 \%$ das sementes foi necessário o uso de estilete para auxiliar a retirada do tegumento e $15 \%$ náo hidrataram o suficiente, o tegumento permaneceu duro na região oposta ao hilo e sua retirada forçada causou danos mecânicos ao embrião (Figura $1 \mathrm{C}$ ).

$\mathrm{O}$ resultado do primeiro teste não foi satisfatório e considerando que, períodos mais longos de embebição implicam em mais tempo gasto para a condução do teste, foram aplicados, a posteriori, dois métodos escarificadores para facilitar a retirada do tegumento.

O pré-condicionamento constou da uniáo de dois métodos: o desponte na região oposta ao hilo seguido do lixamento nas laterais, com o mesmo tempo de embebição e aumento da temperatura para $30^{\circ} \mathrm{C}$. Este método apresentou $100 \%$ de êxito, sendo o tegumento retirado sem qualquer dano mecânico ao embriáo (Figura 1D-F).

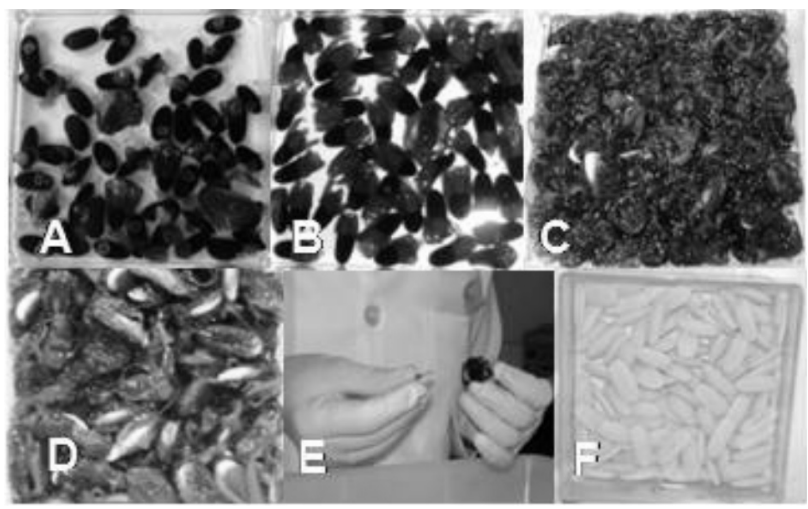

Figura 1 - Pré-condicionamento em sementes de Parkia velutina Benoist. A - Punção, B - Desponte, C - Lixa nas laterais, D - Desponte + Lixa nas laterais, $\mathrm{E}$ - Retirada do tegumento após procedimento, $\mathrm{F}$ - Embrióes prontos para a coloração.

Segundo Piana et al. (1992), a rapidez na avaliação de sementes proporciona vantagens, como a possibilidade de descarte de lotes com qualidade inadequada. Sementes de Tabebuia serratifolia e Tabebuia impetiginosa submetidas ao teste de tetrazólio obtiveram resultado em um dia, enquanto o teste de germinação teve duraçấo de 28 dias (Oliveira $e t$ al., 2005).

A eficiência do teste tetrazólio em avaliar a viabilidade e vigor das sementes está relacionada ao desenvolvimento de metodologia adequada para cada espécie, de modo a definir as condiçôes mais apropriadas para o preparo e o pré-condicionamento e coloração das sementes (Bhering $e t$ al. 2005). Assim, o preparo e o pré-condicionamento das sementes antes da coloração são fatores decisivos.

\section{COLORAÇÃO DAS SEMENTES}

As sementes submetidas à concentração de $0,1 \%$ de tetrazólio não coloriram o suficiente para a correta interpretaçáo dos resultados como pode ser observado na Figura 2A. Para avaliar as classes de viabilidade, o tratamento $0,1 \%$ foi descartado da análise. As concentraçóes de $0,5 \%$ e $1 \%$ foram suficientes para colorir os embrióes de P. velutina (Figura 2B e C).

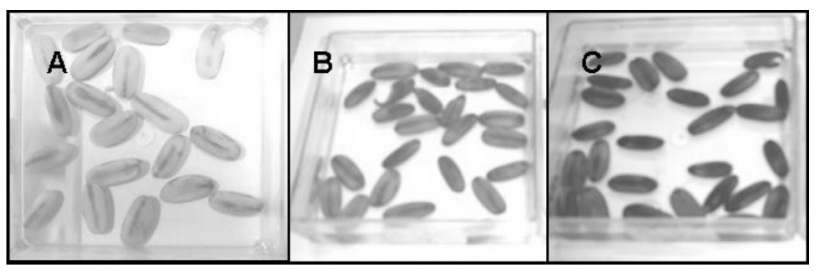

Figura 2 - Coloração de sementes de Parkia velutina Benoist. sob diferentes concentrações de tetrazólio. A - 0,1\%; B - 0,5\%, C - 1,0\%.

Na Figura 3 são apresentadas as classes de viabilidade estabelecidas no teste de tetrazólio para as sementes de $P$. velutina, onde:

Classes de 1 a 3 identificam sementes viáveis e vigorosas; Classes 4 e 5 as sementes são viáveis, porém, não vigorosas; Classes 6 a 8 englobam sementes que não germinam.

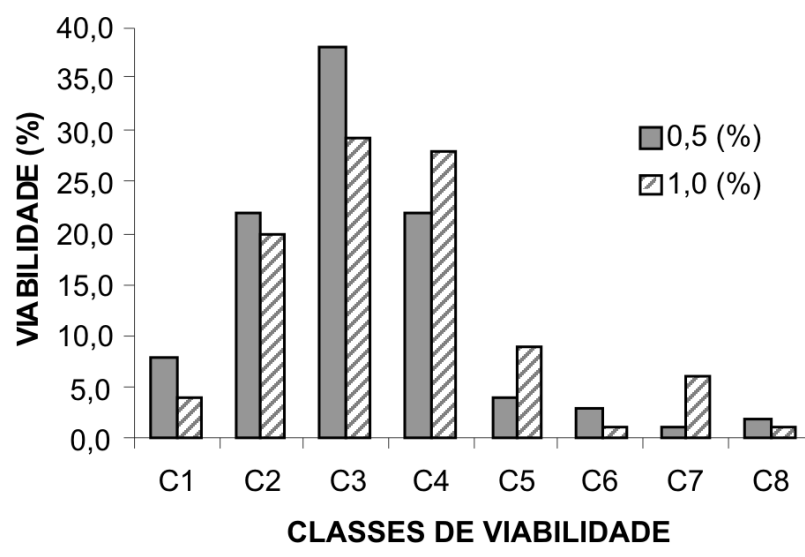

Figura 3 - Classes de viabilidade obtidas no teste de tetrazólio em sementes de Parkia velutina Benoist. em diferentes concentrações (0,5 e 1,0\%).

Maiores valores de viabilidade foram conseguidos nas classes 2, 3 e 4 para ambas as concentraçóes testadas. A viabilidade foi de $22 \%$ nas classes 2 e 4 e $38 \%$ na classe 3 para a concentração a $0,5 \%$. Na concentração a $1 \%$ as classes 2,3 e 4 apresentaram $19 \%$, 29\% e $28 \%$ de viabilidade respectivamente.

As sementes presentes nas classes 1, 2, 3 e 4 apresentaram uma coloração em tom rosado/avermelhado uniforme e aspecto sadio dos tecidos. Em ambas as concentraçôes as classes 5, 6, 7 e 8 mostraram valores de viabilidade inferiores a $10 \%$. Em $75 \%$ das sementes pertencentes as classes $6,7 \mathrm{e}$ 
8 foi observado predação por insetos, causando deterioração nos tecidos dos cotilédones e eixo embrionário. Provavelmente estes insetos já estavam nas sementes na hora da coleta, pois não são pragas de armazenamento. Danos mecânicos também foram observados nestas classes pela coloração vermelha intensa (carmim) nas estruturas do embriáo. A ausência de coloração com tecidos flácidos indicou a morte do embriấo.

Segundo Delouche (2002), neste teste os danos fisiológicos e necroses nas sementes são mostrados em vívidos padrôes de vermelho e branco (ou cor natural da semente), e ficam claramente evidentes os padróes e a natureza progressiva da deterioração.

$\mathrm{Na}$ avaliação individual das sementes, o padrão da coloração das diferentes espécies deve ser observado com cautela. Para P. velutina, após desenvolvimento da coloração, nas duas concentraçóes testadas, a maioria dos embrióes apresentava consistência firme e nítida sanidade, mas parte do eixo embrionário não coloriu (Figura 4A). Este fato foi atribuído aos embrióes de $P$. velutina serem crassos e de consistência carnosa, o que pode ter dificultado a penetração da solução nos tecidos.

A concentração de $0,5 \%$ da solução do tetrazólio permitiu uma coloraçáo mais uniforme dos embrióes, o que facilitou a análise visual da viabilidade (Figura 2B). Sementes submetidas à concentração de $1 \%$ mostraram coloração densa, dificultando a interpretação (Figura 2C). Coloração densa ou escura pode ser o indicativo de estágio avançado de deterioração, o que não pode ser atribuído a espécie testada. Marcos Filho et al. (1987) salientam que várias concentraçôes da solução do tetrazólio podem ser utilizadas na condução do teste, dependendo da espécie avaliada, do método de preparo das sementes e da permeabilidade do tegumento, sendo que, para sementes de espécies florestais, essas concentraçôes variam de $0,5 \%$ a $1 \%$. Em sementes de soja, Costa et al. (1998) observaram alteraçóes no processo de coloraçáo pelo teste de tetrazólio, onde partes expressivas das sementes mostraram características de mosaico, o que foi prejudicial durante a leitura e a interpretação do teste.

\section{VIABILIDADE E VIGOR DAS SEMENTES}

A análise de variância demonstrou haver efeito significativo entre as diferentes concentraçóes de tetrazólio e a germinação das sementes. Na tabela 1 pode-se que a viabilidade apresentada pelo teste de germinaçáo foi superior ao teste de tetrazólio, sendo que a concentração de $0,5 \%$ não diferiu estatisticamente dos demais tratamentos. Para a característica vigor, os resultados do teste de germinação foram significativamente superiores aos do teste de tetrazólio e a concentração de $1 \%$ demonstrou valor inferior aos demais tratamentos, subestimando o vigor das sementes. Portanto,
Tabela 1 - Viabilidade e vigor (\%) das sementes de Parkia velutina Benoist., avaliadas pelo teste de tetrazólio (TZ) em diferentes concentrações $(0,5$ e $1,0 \%)$ e teste de germinação.

\begin{tabular}{lcc}
\hline \multirow{2}{*}{ TRATAMENTOS } & \multicolumn{2}{c}{ CARACTERíSTICAS } \\
\cline { 2 - 3 } & *Viabilidade (\%) & **Vigor (\%) \\
\hline TZ a 0,5\% & 94,0 ab & $68,0 \mathrm{~b}$ \\
TZ a 1,0\% & $90,0 \quad \mathrm{~b}$ & $53,0 \mathrm{c}$ \\
Teste de germinação & $97,0 \mathrm{a}$ & $94,0 \mathrm{a}$ \\
DMS (Tukey) & 7.94 & 7.79 \\
Coeficiente de Variação (\%) & 5.24 & 6.59 \\
\hline
\end{tabular}

Médias seguidas da mesma letra na coluna não diferem entre si a $5 \%$ de probabilidade pelo teste de Tukey.

* Teste de tetrazólio (até classe 5). Característica de germinacão (emissão de raiz). ** Teste de tetrazólio (até classe 3). Característica de germinaçẫo (formação da plântula).

a aplicação do teste de tetrazólio para P. velutina foi eficiente apenas para avaliar a viabilidade do lote.

A formação de plântula normal foi o parâmetro utilizado para avaliar o vigor no teste de germinaçấo, e o lote estudado se mostrou bastante vigoroso, o mesmo não aconteceu para o teste de tetrazólio nas duas concentraçóes testadas, onde o parâmetro utilizado foram as diferentes classes, conforme metodologia de França Neto et al. (1998). Geralmente os resultados do teste de tetrazólio se aproximam do teste de germinação ou os valores de tetrazólio são maiores. Segundo Oliveira et al. (2005), isso acontece porque no teste de tetrazólio somente o embrião é avaliado, não considerando a influência das estruturas externas das sementes nos resultados

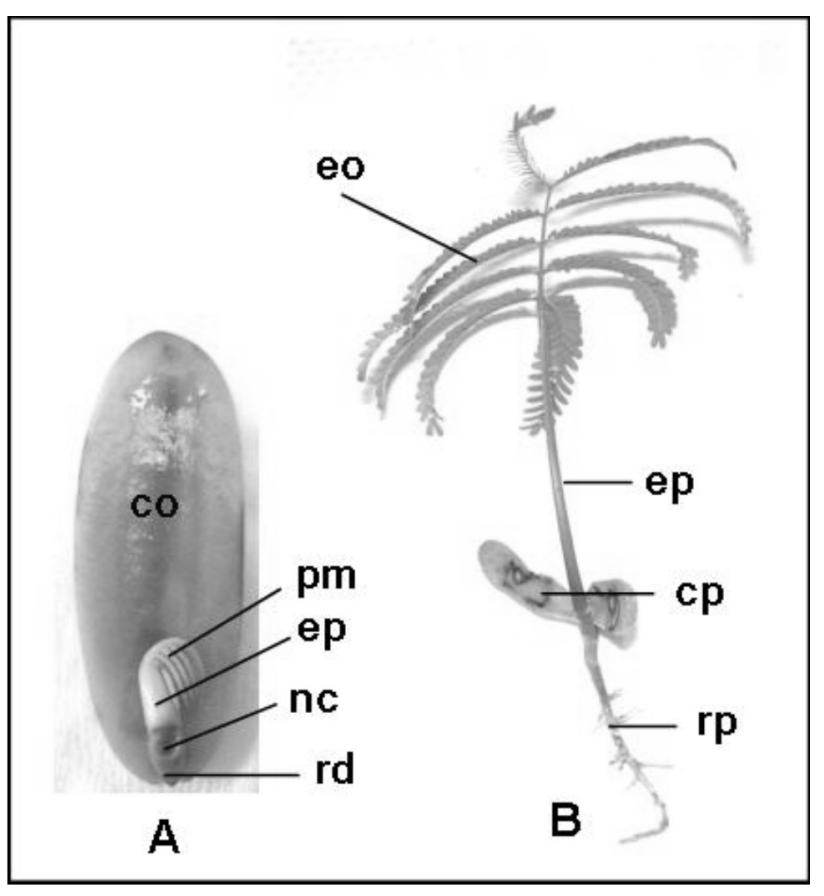

Figura 4 - Características do embrião e da plântula de Parkia velutina Benoist. A - Embrião (co - cotilédone, ep - epicótilo, nc - nó cotiledonar, pm - plúmula, rd - radícula); B - Plântula (cp - cotilédone predado por insetos, eo - eofilo, ep - epicótilo, rp - raiz primária). 
dos testes de germinação, como a possíveis infestaçôes com patógenos no lote.

As sementes maduras de $P$. velutina concentram suas reservas no próprio embrião, em seus grandes cotilédones carnosos, além disso, seu eixo embrionário é completamente desenvolvido, podendo ser distinguido em radícula, hipocótilo, epicótilo e plúmula (Figura 4A). Portanto, mesmo que os cotilédones sejam injuriados em até $50 \%$, o restante da reserva é suficiente para que durante a germinação o embriấo se transforme em uma plântula normal e vigorosa (Figura 4B). Essa característica inerente à espécie provavelmente influencia na interpretação dos resultados quando se utiliza as diferentes classes na determinação do vigor das sementes.

\section{CONCLUSÕES}

A escarificação por desponte no lado oposto ao hilo, seguida de lixamento nas laterais da semente, embebidas em $200 \mathrm{ml}$ de água destilada por 16 horas a temperatura de $30^{\circ} \mathrm{C}$, apresentou eficiência no pré-condicionamento de sementes de P. velutina.

O teste de tetrazólio na concentraçáo de $0,5 \%$ pode ser utilizado para avaliar a viabilidade das sementes de P. velutina, como complemento ao teste de germinaçáo. Porém o teste de tetrazólio não permite avaliar o vigor em sementes de $P$. velutina, mas pode ser utilizado na caracterizaçâo de injúrias, ocasionadas pelo ataque de insetos e danos mecânicos por ocasião da coleta e armazenamento das sementes.

\section{AGRADECIMENTOS}

Os autores agradecem ao CTPETRO/FINEP/UEA pelo apoio nas pesquisas do projeto "Seleção e monitoramento ecofisiológico de espécies arbóreas para revegetação experimental de áreas degradadas de exploraçáo e produção da Petrobrás/AM" e à Fundação de Apoio à Pesquisa do Estado do Amazonas - FAPEAM, pelo apoio nas pesquisas com o gênero Parkia.

\section{BIBLIOGRAFIA CITADA}

Araújo-Neto, J.C.; Aguiar, I.B.; Ferreira, V.M.; César Paula, R. 2002. Caracterização morfológica de frutos e sementes e desenvolvimento pós-seminal de monjoleiro (Acacia polyphylla DC.). Revista Brasileira de Sementes, 24 (1): 203-211.

Bhering, M.C.; Dias, D.C.F.S.; Barros, D.I. 2005. Adequação da Metodologia do Teste de Tetrazólio para Avaliação da Qualidade Fisiológica de Sementes de Melancia. Revista Brasileira de Sementes, 27 (2): 176-182.
Costa, N.P. da; Franca Neto, J.B.; Krzyzanowski, F.C. 1998. Avaliação de metodologia alternativa para o teste de tetrazólio para sementes de soja. Sci. agric. 55 (2): 305-312.

Delouche, J.C. 2002. Germinação, Deterioração e Vigor da Semente. Revista Seed News, 6 (6): 45-48.

França Neto, J.B. 1999. Teste de tetrazólio para determinação do vigor de sementes. In: Krzyzanowiski, F.C.; Vieira, R.D.; França Neto, J.B. Vigor de Sementes: conceitos e testes. Londrina: ABRATES, 218pp.

França Neto, J.B.; Krzyzanowiski, F.C.; Costa, N.P. 1998. The Tetrazolium test for soybean seeds. Londrina: EMBRAPA CNPSo. 71pp. (Documentos 115).

Hopkins, H.C. 1986. Parkia (Leguminosae: Mimosoideae). Flora Neotrópica: New York Botanical Garden, New York, Monografia, p. 93-98.

Macedo, W.R.; 2006. Qualidade da Semente Forrageira e a Garantia de Sucesso na Formação da Pastagem. UFSC - Universidade Federal de Santa Catarina, Florianópolis. 24pp.

Marcos Filho, J.; Cícero, S.M.; Silva, W.R. 1987. Avaliação da Qualidade Fisiológica das Sementes. Piracicaba: FEALQ, 230pp.

Mendes, A.M.S.; Ramos, M.B.P.; Melo, M.G. 2006. Características Tecnológicas de Sementes de Parkia velutina Benoist (Leguminosaea-Mimosoideae). XX Congresso Panamericano de Sementes, 14 a 17/08 de, Fortaleza, Ceará.

Oliveira, L.M.; Carvalho, M.L.M.; Davide, A.C. 2005. Teste de Tetrazólio para Avaliação de sementes de Peltophorum dubium (Sprengel) Taubert Leguminosae-Caesalpinoideae. Cerne, 11 (2): 159-166.

Oliveira, L.M.; Carvalho, M.L.M.; Nery, M.C. 2005. Caracterização Morfológica, Viabilidade e Vigor de Sementes de Tabebuia áurea (Silvia Manso) Benth. \& Hook. F. ex. S. Moore. Revista Árvore, 3 (1): 25-32.

Oliveira, E.C.; Pinã-Rodrigues, F.C.M.; Figliolia, M.B. 1989. Proposta para a padronização de metodologias em Análise de Sementes Florestais. Revista Brasileira de Sementes, Brasília, 11 (1/2/3): 1-42.

Rosinha, R.C. Demanda em Pesquisa na Área de Produção de Sementes Básicas. 1981. Revista Brasileira de Sementes, 3 (2): 93-103.

Silva, M.F.; Souza, L.A.G.; Carreira, L.M.M. 2004. Nomes Populares das Leguminosas do Brasil. Manaus, AM: EDUA, 236 pp.

Vieira, A.H.; Martins, E.P.; Pequeno, P.L.L.; Locatelli, M.; Souza, M.G. 2001. Técnicas de Produção de sementes Florestais. Rondônia: EMBRAPA/CPAF. 4p. (Circular Técnico, 205).

Recebido em 24/03/2008

Aceito em 27/03/2009 